\title{
Cerebrospinal fluid GABA levels in various neurological and psychiatric diseases
}

\author{
HIROO KURODA, NORIO OGAWA, YASUHIDE YAMAWAKI, \\ ITARU NUKINA, TADASHI OFUJI, MITSUTOSHI YAMAMOTO,* \\ SABURO OTSUKI*

\begin{abstract}
From the Third Department of Internal Medicine and the Department of Neuropsychiatry,* Okayama University Medical School, Okayama, Japan
\end{abstract}

SUMMARY Cerebrospinal fluid gamma-aminobutyric acid (CSF-GABA) was analysed by radioreceptor assay in 16 normal controls and 84 patients with various neurological and psychiatric diseases. In patients with spinocerebellar degeneration, neuro-Behçet's syndrome and Parkinson's disease, CSF-GABA levels were decreased. On the other hand, increased CSF-GABA levels were detected in patients with meningitis.

Gamma-aminobutyric acid (GABA), a putative inhibitory neurotransmitter, is distributed throughout the brain and spinal cord. ${ }^{1-4}$ Recent studies suggest that a disorder of GABA metabolism may exist in certain neurological and psychiatric diseases. $^{5-9}$ Since cerebrospinal fluid (CSF) is believed to be formed in the choroid plexus and is in contact with both the brain and spinal cord. it may reflect disorders of central nervous system (CNS). To gain further insight into various neurological and psychiatric diseases, we have measured GABA concentrations in CSF by radioreceptor assay.

\section{Methods}

Controls The control group consisted of normal volunteers and patients in hospital without neurological or psychiatric disease and who were not receiving drugs. In the normal controls there were 8 men and 8 women; the mean age was $44 \pm 17 \mathrm{yr}($ mean \pm SEM).

Patients Eighty-four patients with various neurological and psychiatric diseases were investigated in this study. The figure shows the diagnoses of the patients.

Address for reprint requests: Dr Hiroo Kuroda, Third Department of Internal Medicine, Okayama University Medical School, Okayama 700, Japan.

Received 9 May 1981 and in revised form 24 September 1981 Accepted 3 October 1981
Procedures All individuals were maintained on absolute bed rest and oral intake was avoided for the previous 15 hours. Some of these patients were not medicated. In the others drug therapy was stopped for at least 14 days preceding lumbar puncture with the exception of those with epilepsy. Lumbar puncture were performed at 9 am in the standard fashion with the patients in the lateral decubitus position. Ten $\mathrm{ml}$ of CSF was withdrawn and the final $5 \mathrm{ml}$ was immediately frozen in an acetone dry ice tube and kept at $-70^{\circ} \mathrm{C}$ until assay.

Assay GABA radioreceptor assay was performed principally by the method of Enna et al. ${ }^{10}$ For the receptor preparation, crude synaptic membrane was prepared from whole rat brain using a modification of the method of De Robertis et al. ${ }^{11}$ Briefly, Sprague-Dawley rats (200-250 g) were decapitated and the whole brains were immediately removed. The tissue was homogenised in $10 \mathrm{vol}$ of icecold $0.32 \mathrm{M}$ sucrose by Brinkman Polytron PT-10 homogeniser for $20 \mathrm{~s}$ and the homogenate was centrifuged at $900 \mathrm{~g}$ for $10 \mathrm{~min}$. The supernatant was further centrifuged at $11500 \mathrm{~g}$ for $20 \mathrm{~min}$, and the pellet was resuspended in $10 \mathrm{vol}$ of Tris- $\mathrm{HCl}$ buffer $(50 \mathrm{mM}$ Tris$\mathrm{HCl}$ buffer, pH 7.6) and kept at $-70^{\circ} \mathrm{C}$ until used. Before analysis, this preparation was thawed and homogenised with a glass-homogeniser in $100 \mathrm{vol}$ of Tris- $\mathrm{HCl}$ buffer, then centrifuged at $50000 \mathrm{~g}$ for $20 \mathrm{~min}$. The supernatant was discarded and the pellet was resuspended in $100 \mathrm{vol}$ of Tris- $\mathrm{HCl}$ buffer containing $0.05 \%$ Triton $\mathrm{X}-100$ and incubated in shaking water bath at $37^{\circ} \mathrm{C}$ for $30 \mathrm{~min}$, then centrifuged at $50000 \mathrm{~g}$ for $20 \mathrm{~min}$, twice. The pellet was resuspended in $20 \mathrm{vol}$ of Tris-HCl buffer to make a tissue concentration of approximately $0.6 \mathrm{mg}$ protein $/ \mathrm{ml}$. For the GABA radioreceptor assay, $0.5 \mathrm{ml}$ 

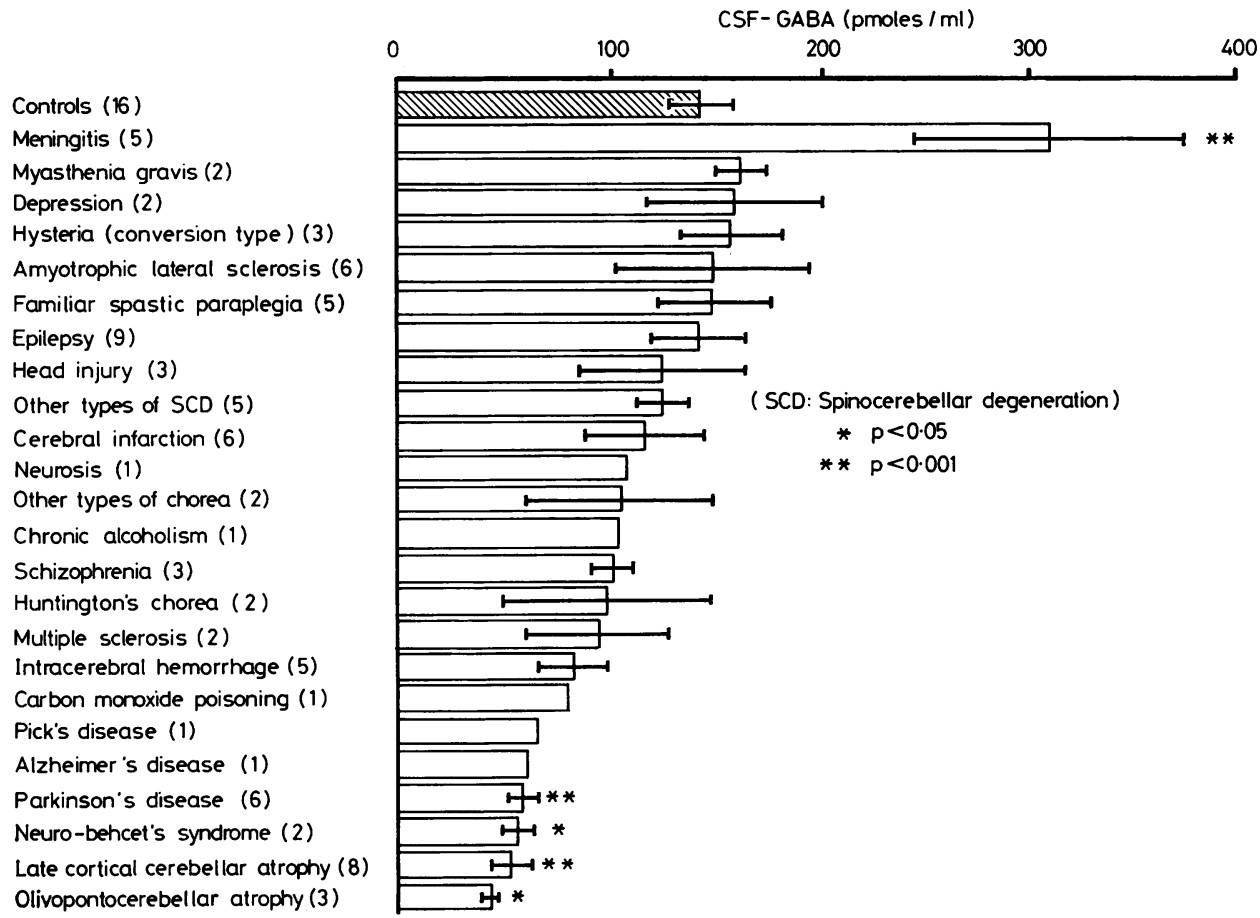

Figure Cerebrospinal fluid gamma-aminobutyric acid (CSF-GABA) levels in normal controls and in patients with various neurological and psychiatric diseases. Each bar represents mean $\pm S E M$. Asterisk indicates statistical significance compared with controls by Student's t test.

( ): number of cases.

portion of this membrane suspension was placed into glass tube containing $0.2 \mathrm{ml}$ of CSF, $0.2 \mathrm{ml}$ of Tris- $\mathrm{HCl}$ buffer and $0.1 \mathrm{ml}$ of $6.4 \mathrm{nM}{ }^{3} \mathrm{H}-\mathrm{GABA}$ (Amersham, specific activity $57 \mathrm{Ci} / \mathrm{mmol})$. The samples were incubated in ice for $30 \mathrm{~min}$ and the reaction was terminated by filtration through glass fibre filters (Whatman GF/C) under reduced pressure. Finally, each filter was washed twice with $5 \mathrm{ml}$ of cold Tris- $\mathrm{HCl}$ buffer and then placed into a scintillation vial with $10 \mathrm{ml}$ of scintillation fluor for counting. All samples were analysed in duplicate.

\section{Results}

With the radioreceptor assay, as little as $5 \mathrm{pmoles} / \mathrm{ml}$ of GABA could be measured reliably. The results of this study are shown in the figure. In normal controls, the mean ( \pm SEM) GABA level in CSF was $143 \pm$ 16 pmoles $/ \mathrm{ml}$. The mean CSF-GABA level in females was $159 \pm 23 \mathrm{pmoles} / \mathrm{ml}(\mathrm{N}=8)$ and that in males was $127 \pm 22 \mathrm{pmoles} / \mathrm{ml}(\mathrm{N}=8)$, which were not different. There was no correlation $(r=0 \cdot 16)$ between age and CSF-GABA level in normal controls. Among the patients tested, the lowest GABA level in CSF was observed in patients with olivopontocerebellar atrophy and late cortical cerebellar atrophy, which were $46 \pm 2$ pmoles $/ \mathrm{ml}$ and $55 \pm 11$ pmoles $/ \mathrm{ml}$ respectively. The next lowest CSF-GABA level was seen in patients with neuro-Behçet's syndrome which was $57 \pm 8$ pmoles/ ml. In patients with Parkinson's disease, Alzheimer's disease and Pick's disease, the CSF-GABA levels were also quite low, which were between 60 and 70 pmoles $/ \mathrm{ml}$. On the other hand, we found an increased CSF-GABA level in patients with meningitis, which was $309 \pm 65$ pmoles $/ \mathrm{ml}$. In all other diseases tested, CSF-GABA levels did not differ from normal controls.

\section{Discussion}

As described above, we could measure CSF-GABA level down to $5 \mathrm{pmoles} / \mathrm{ml}$ by radioreceptor assay; the CSF-GABA level in normal controls was slightly lower than that which some other groups have reported. ${ }^{7213}$ The lowest CSF-GABA level was seen in patients with olivopontocerebellar atrophy and late cortical cerebellar atrophy. Both these illnesses are characterised by degeneration of the cerebellum. The GABA concentration in the 
cerebellum is low but the total GABA content is high. Therefore, the destruction of cerebellum causes a decrease of total cerebellar GABA content. The low CSF-GABA level in these two diseases, therefore, may be associated with the degeneration of cerebellum, and the CSF-GABA level may suggest the severity of these diseases. Indeed, the CSFGABA level was correlated with the degree of atrophy of the cerebellum on CT scans. Manyam et al also have reported decreased CSF-GABA levels in cerebellar degeneration. ${ }^{14}$ The CSF-GABA level in neuro-Behçet's syndrome was low, so we could differentiate this type of Behçet's syndrome from other types. Furthermore, measuring CSFGABA level might be a useful method to diagnose neuro-Behçet's syndrome at an early stage.

The CSF-GABA level in Parkinson's disease was low, about $43 \%$ of normal controls. Glutamic acid decarboxylase (GAD) catalyses the decarboxylation of glutamic acid to GABA, and GAD regulates the steady-state concentration of GABA. The highest concentrations of GAD and GABA are in substantia nigra and globus pallidus. ${ }^{15}$ The activity of GAD is decreased in certain areas of the brain in patients with untreated Parkinson's disease and is almost normal in brains of patients treated with levodopa, whereas brain levels of GABA are unchanged in both groups of Parkinson's disease. ${ }^{16} 17$ The CSF-GABA level in Parkinson's disease in the present study was very low compared with that in Enna et al's report, which analysed levodopatreated patients. ${ }^{13}$ The decrease of CSF-GABA in Parkinson's disease may be due to the change of GABA turnover because patients in this study were not treated with levodopa for at least 14 days.

Alzheimer's disease and Pick's disease are characterised by dementia and severe cerebral cortical degeneration. The CSF-GABA level in these diseases was quite low, almost the same as in Parkinson's disease. In cerebral cortex, the GABA concentration is low and is about $40 \%$ of that in substantia nigra and globus pallidus. But the total GABA content is high because of the total weight of the cerebral cortex. The total GABA content in cerebral cortex thus becomes lower with the progress of these diseases. There was an increase of CSFGABA level in patients with meningitis, which was about twice as high as that of normal controls. These data suggest that inflammation of the meninges caused by the infection may change the function of the blood-brain-barrier, so that GABA can be easily transported from brain to CSF or change the function of GABA metabolism in brain. Buryakova et al have reported that CSF-GABA was detected in patients with bacterial meningitis, but not found in the CSF with serous meningitis and normal controls in childhood. They suggested that the detection of CSF-GABA might be used as a test to differentiate between serous and bacterial meningitis. ${ }^{18}$ In the present study, almost of all patients were adults with viral infection. It will be necessary to analyse many more patients with various types of meningitis before definite conclusions can be drawn.

This work was supported in part by a Research Grant for the Intractable Diseases from the Ministry of Health and Welfare of Japan and a grant-in-aid for scientific research from the Japanese Ministry of Education.

\section{References}

${ }^{1}$ Roberts E, Frankel S. $\gamma$-aminobutyric acid in brain, its formation from glutamic acid. $J$ Biol Chem 1950; 187:55-63.

2 Baxter CF. The nature of GABA. In: Lajtha A, ed. Handbook of Neurochemistry. New York: Plenum Press, 1970;3:289-353.

${ }^{3}$ Roberts E, Kuriyama K. Biochemical-physiological correlations in studies of $\gamma$-aminobutyric acid system. Brain Res $1968 ; 8: 1-35$.

${ }^{4}$ Robinson N, Wells F. Distribution and localization of sites of gamma-aminobutyric acid metabolism in the adult rat brain. $J$ Anat 1973;114:365-78.

"Roberts E, Chase T, Tower D (eds). GABA in Nervous System Function. New York: Raven Press, 1976.

${ }^{6}$ Enna SJ, Stern LZ, Wastek GJ, et al. Neurobiology and pharmacology of Huntington's disease. Life Sci 1977;20:205-12.

' Manyam NVB, Hare TA, Katz L, Glaeser BS. Huntington's disease: Cerebrospinal fluid GABA levels in at-risk individuals. Arch Neurol 1978;35: 728-30.

${ }^{\star}$ Meldrum BS. Epilepsy and gamma-aminobutyric acid mediated inhibition. In: Pfeiffer CC, Smythies $\mathrm{JR}$, eds. International Review of Neurobiology, vol 17. New York: Academic Press, 1975:1-36.

"Tower DB. GABA and seizures: Clinical correlates in man. In: Roberts $\mathrm{E}$, Chase $\mathrm{TN}$, Tower DB, eds. $G A B A$ in Nervous System Function. New York: Raven Press, 1976:461-78.

1" Enna SJ, Snyder SH. A simple, sensitive and specific radioreceptor assay for endogenous GABA in brain tissues. J Neurochem 1976;26:221-4.

${ }^{11}$ De Robertis E, Pellegrio De Iraldi A, Rodoriguez De Lores G, Salganicoff L. Cholinergic and noncholinergic nerve endings in rat brain.-I. Isolation and subcellular distribution of acetylcholine and acetylcholinesterase. J Neurochem 1962;9:23-35.

1.2 Manyam NVB, Katz L, Hare TA, Gerber JC, Grossman MH. Levels of $\gamma$-aminobutyric acid in cerebrospinal fluid in various neurologic disorders. Arch Neurol 1980;37:352-5.

${ }^{13}$ Enna SJ, Stern LZ, Wastek GJ, Yamamura HI. Cerebrospinal fluid gamma-aminobutyric acid variations in neurological disorders. Arch Neurol 
$1977 ; 34: 683-5$.

${ }_{14}$ Manyam NVB, Hare TA, Katz L. Cerebrospinal fluid GABA levels in involuntary movement disorders. Brain Res Bull 1980;5 Suppl 2:741-5.

${ }^{15}$ Fahn S, Cote LJ. Regional distribution of gammaaminobutyric acid (GABA) in brains of the rhesus monkey. J Neurochem 1968;15:209-13.

${ }^{16}$ Lloid KG, Hornykiewicz O. L-glutamic acid decarboxylase in Parkinson's disease: Effect of L-dopa therapy. Nature 1973;243:521-3.

${ }^{17}$ Hornykiewicz O, Lloid KG, Davidson L. The GABA system and function of the basal ganglia and Parkinson's disease. In: Roberts E, Chase TN, Tower DB, eds. GABA in Nervous System Function. New York: Raven Press, 1976:479-85.

${ }^{18}$ Buryakova AV, Cand MS, Sytinsky IA. Amino acid composition of cerebrospinal fluid in acute neuroinfections in children. Arch Neurol 1975;32:28-31. 